\title{
E. Hywel Evans and Mike. E. Foulkes: Analytical Chemistry. A Practical Approach
}

\author{
Edward R. Adlard ${ }^{1}$
}

๑) Springer-Verlag GmbH Germany, part of Springer Nature 2019

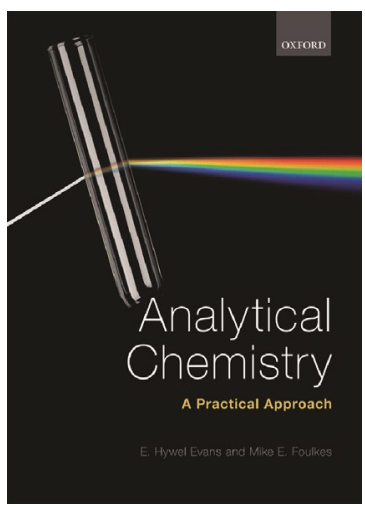

\author{
Bibliography \\ Analytical Chemistry. A Practical Approach \\ E. Hywel Evans, Mike. E. Foulkes \\ Oxford University Press, Oxford, UK, 2019, pp xviii + 255 \\ ISBN 978-0-19-965179-9 \\ GBP 34.99
}

Potential purchasers of this book should not expect a normal textbook of analytical chemistry. Various well-known techniques such as chromatography and mass spectrometry are covered in a few pages which give outlines of the scope of the techniques but little or no details. There are only nine chapters with a little over 200 pages, an appendix and an index. If my memory serves me correctly, the book follows along the lines of the former Analytical Chemistry by Open Learning (ACOL) book series, published 20-25 years ago, in that there are questions for the reader to answer at the end of each chapter and the correct answers are given at the end of the book. The front of the book (pages xvi-xviii) carries a useful list of abbreviations.

After the introductory chapter, Chapters 2 and 3 deal with sampling and sample preparation. As has been pointed out by others, sample preparation can be the time-limiting step of an analysis. Chapter 4 gives a brief account of the scope of the various analytical techniques available and this is followed by one on calibration and quantitation. Chapter 6 is about reference materials and standards. Near the end of

Edward R. Adlard

e.adlard77@btinternet.com

1 Burton, UK my active analytical career I developed a method which had such severe operating conditions (and important financial consequences) that it was necessary to run a standard after every real sample but this was an extreme case and usually one standard for every ten samples is adequate.

In the early days of GC quantitative analysis of a complex hydrocarbon mixture giving $200+$ peaks was a timeconsuming undertaking so such samples were not analysed more than in duplicate. Development of the PC and later the work of Cramers at Eindhoven and Lynch at BP on highspeed GC meant that mathematical analysis of multiple runs was a meaningful possibility. I never got beyond standard deviation and must admit to a total ignorance of statistical analysis. The last chapters on the book which discuss such aspects of data manipulation would have been very useful to me when I was a practicing analyst.

Overall, this book gives information on a range of topics not readily available in standard works on analysis and is a must buy for all analytical chemists. It is also relatively inexpensive.

Publisher's Note Springer Nature remains neutral with regard to jurisdictional claims in published maps and institutional affiliations. 